\title{
T Regulatory Cells and BCG as a Vaccine against Tuberculosis: An Overview
}

\author{
Om Parkash \\ Department of Immunology, National JALMA Institute for Leprosy and Other Mycobacterial Diseases, \\ Tajganj, Agra, India \\ Email: om1234@gmail.com; op v3@yahoo.com
}

Received 9 February 2015; accepted 18 April 2015; published 24 April 2015

Copyright (C) 2015 by author and Scientific Research Publishing Inc.

This work is licensed under the Creative Commons Attribution International License (CC BY). http://creativecommons.org/licenses/by/4.0/

(c) (i) Open Access

\begin{abstract}
Bacille Calmette Guerin (BCG), which has been used since 1921 as the only vaccine against tuberculosis (TB), protects poorly, if at all, against pulmonary tuberculosis among adults in high incident developing countries. This failure has been attributed to the possible down modulating action of $T$ regulatory cells (Tregs), which can be stimulated by environmental mycobacteria and expanded by BCG vaccination. Tregs induced at the site of BCG vaccination may interfere with protection against tuberculosis. This communication describes the contribution of Tregs towards dampening the efficacy of BCG and plausible approaches to countering this down modulating effect of Tregs. Probably, antigen specific inhibition of the local recruitment of Tregs whilst avoiding generalised disturbance of immune homeostasis could prove to be worthwhile. Alternatively, drugs with short half life may achieve more acceptable transient inhibition of Tregs function than the prolonged action of monoclonal antibodies. Evolving novel safe strategies is a challenge for developing a better anti TB vaccine.
\end{abstract}

\section{Keywords}

BCG, Vaccine, Tuberculosis, T Regulatory Cells

\section{Introduction about Tuberculosis}

\subsection{Tuberculosis Infection}

Tuberculosis (TB) is an airborne chronic disease caused by inhalation of M. Tuberculosis (MTB), which is entangled in the respiratory tract fluid droplets and exhaled (through coughing, sneezing, talking, singing, etc.) in the atmospheric air from the lungs by the pulmonary cavitary TB patients [1]. After reaching the alveoli of lungs, the viable MTB bacilli are engulfed by macrophages, where they multiply. During this process of host-MTB in- 
teraction, pro-inflammatory cytokines are produced, locally, inside the infected tissue, by these invaded macrophages. This further leads to formation of granuloma through recruitment of mononuclear cells (primarily macrophages and lymphocytes) from blood vessels irrigating the invaded tissue. Granuloma is a local accumulation of cells surrounding the infected macrophages (in the centre) by foamy giant cells, macrophages and lymphocytes, where lymphocytes get positioned in the periphery demarcating the boundary of the raised structure. In majority of the infected persons, the infection is contained at this stage of primary infection and such infected individuals remain asymptomatic and non infectious which is called as latent tuberculosis infection (LTBI). However, in immunosuppressive situations the containment due to granuloma becomes weak. As a result, the kernel of the granuloma caseats followed by liquefaction and then by formation of cavity which may rupture in the alveoli of the bronchi. This results in the development of productive cough and viable MTB bacilli are exhaled out from the airways. Depending upon the intensity and extension of inflammatory response, lung tissues are destroyed resulting in impairment of lung function (i.e. problem in breathing due to decreased exchange of gases during respiration) which eventually may cause death of the untreated patient.

\subsection{Global Prevalence}

TB is a major global health problem with a slow decline in its load. It is estimated that about one third of the world's population (a majority in the developing countries) is infected with MTB. According to the latest report of WHO [2] in 2013: (a) about 9 million new active TB were reported of which about 50\% were from SouthEast Asia and Western Pacific Regions. India alone accounted for about $24 \%$ of all the newly detected TB cases followed by China which accounted for $11 \%$ of the total cases; (b) of the new TB cases, 1.1 million were estimated to be HIV positive and 480,000 were reported to be multidrug-resistant (resistant at least to rifampin and isoniazid with and without resistant to other first line drugs); (c) about 1.5 million persons died due to TB of which about 360,000 were HIV positive. Sub-Saharan Africa has the highest rates of active tuberculosis per capita, driven primarily by the HIV epidemic; (d) among the multi drug resistant TB (MDR-TB) cases about 9\% were extensively drug resistant (XDR-TB; which are MDR-TB cases who are resistant to fluoroquinolones as well as to any one of the injectable anti-tuberculosis drugs like: kanamycin, amikacin, and capreomycin) TB cases; (e) more than half of the drug resistant cases were reported from India, China and the Russian Federation alone; (f) from 1990-2013, the reductions in global TB mortality and prevalence rates have occurred to the tune of about $45 \%$ and $41 \%$ respectively. Report indicates that existence of drug resistance and HIV epidemic has posed strong challenges towards global control of TB.

\subsection{Clinical Manifestations}

Primarily, tuberculosis is a disease of lungs; however, any organ may be affected by it. After infection with MTB, only $5 \%$ - $10 \%$ of infected persons develop active TB whereas, remaining more than $90 \%$ of the subjects succeeds in containing the pathogen and thereby resulting in asymptomatic LTBI. In case of TB, chronic cough and sputum production are some of the leading clinical symptoms. However, depending upon the immunity (the risk increases with extent of immunodeficiency and immune-suppression) of the host, $18 \%$ - $42 \%$ of people develop extra-pulmonary TB and about $2 \%$ of all TB cases and about $20 \%$ of extra pulmonary TB cases accounts for a disseminated form of TB called milliary TB. In extra-pulmonary TB any organ (e.g. lymphoid tissues, central nervous system, bones, joints, pleura and genitourinary system, etc.) of body may be involved and the clinical manifestations may vary depending upon the affected organ. On the other hand, in case of milliary TB, dissemination of MTB infection may occur throughout the body and thus may involve multiple organs. Clinical manifestations of the milliary TB are non-specific and hence, difficult to diagnose it. Nonetheless, the presence (for more than six weeks) of any one or more of the classical clinical symptoms, viz: chronic cough, fever, weight loss, anorexia and night sweats may point out the probable occurrence of TB which may further be confirmed through positive response to anti-tuberculosis treatment and laboratory based investigations [3] [4].

\subsection{Predisposing Factors}

Normally, 90\% of the subjects do not develop TB after infection. However, the important factors [3] [5] [6] responsible for predisposition of an individual to develop this disease are: (i) co-infection with human immunodeficiency virus is the most notable cause for progression to active disease; (ii) underlying immunosupressive conditions like: presence of uncontrolled diabetes mellitus, organ transplantation, renal failure, sepsis, cancer and 
cancer chemotherapy, silicosis and usage of immunosuppressive drugs; (iii) age of the individuals: 65 years old and above; and babies/children less than 5 years old; (iv) malnutrition; (v) genetics, race, and ethnic background of an individual; (vi) virulence of the M. tuberculosis strain; (vii) behavioural factors like : alcoholism, tobacco smoking and drug abuse, etc. Additionally, there are several factors which make an individual prone to contract MTB infection: (i) close contacts with patients having infectious TB, especially with high bacillary load in sputum; (ii) working or residing with facilities like: homeless shelters, hospitals, nursing homes, residential homes for TB and HIV infected persons; (iii) indoor air pollution; (iv) crowded places; (v) confined places like prison, etc.

\subsection{Treatment}

Persons having latent tuberculosis infection are prone (due to down modulation of their immunity) to progression to active TB. Hence, to prevent this happening, persons with LTBI are treated with isoniazid for six to preferably nine months. However, in case of HIV infected LTBI the treatment is for longer duration. On the other hand, patients with drug sensitive active TB are treated with regimens consisting of first line drugs: isoniazid, rifampin, pyrazinamide, and ethambutol for 2 months followed by 4 months by rifampicin and isoniazid. The efficacy rate is $90 \%$ - 95\% if treated under supervision and maintained compliance during the treatment period. Regarding tuberculosis and HIV co-infected individuals anti-retroviral therapy is recommended after start of anti TB treatment. MDR-TB is treated by formulating regimens based on the first line and second line antituberculosis drugs [e.g. second line drugs (i) ethionamide or prothionamide; (ii) cycloserine or para-aminosalicylic acid (in case cycloserine cannot be used); (iii) fluoroquinolone; and (iv) a parenteral agent. Additionally, pyrazinamide from first line drugs.]. Initially, the regimens for individualized therapy are selected based on local disease pattern, a known source case, prior exposure to anti-TB drugs, and thereafter on drug susceptibility test result. Such therapy should be administered for at least 20 months in patients who have not received previous treatment for multidrug-resistant tuberculosis and for up to 30 months in those who have received previous treatment. It would be worth mentioning here that second-line drugs are more toxic and expensive when compared with the first-line drugs for standard anti-TB regimen. Like MDR-TB the treatment regimen for XDR-TB is designed based on the suitable first and second lines drugs. Sometimes, it may need involving non established highly toxic drugs as well. Nevertheless, designing treatment regimen for XDR-TB patients is a challenging task [3] [7].

\section{Why Anti TB vaccine?}

Worldwide, intensive efforts to combat tuberculosis are being made. As a part of this effort, the currently available anti TB drugs require minimum 6 - 9 months in treating the patients. Unfortunately, emergence of multiand extensively drug-resistant TB and HIV infection have hindered the progress and have raised future apprehension on TB control by using available drugs. Thus, TB is considered to be a great threat, especially for the developing countries, through weakening the economic and productive resources for poor countries to escape poverty. It is estimated that TB costs about $€ 290$ billion/year to the global economy [8]. Considering these facts in view, an effective preventive vaccine can prove to be the most economic tool for mitigating TB epidemic.

\section{BCG as a Vaccine against Tuberculosis}

BCG (Bacille Calmette Guerin) is an attenuated strain of Mycobacterium bovis that was isolated nearly a century ago [9]. The use of BCG for human vaccination against tuberculosis was initiated in 1921 and is in use till now, while alternative subunit vaccines are at different stages of intensive research. BCG induces T-cell helper type-1 (Th1) immunity for protection of the host from M. tuberculosis infection. BCG has been found to be $60 \%$ - 80\% protective against severe forms (disseminating and meningeal) of TB in children; however, its efficacy against pulmonary tuberculosis in adults is inconsistent and varies from $0 \%-80 \%$ in different geographical regions [10] [11]. The poor performance of BCG in developing countries, where rates of TB are much higher, is very discouraging. The reasons being considered are: strain differences in BCG, prevalence of environmental mycobacteria, genetics of host, nutritional factors and presence of helminthic co-infections, etc. [12]. Of the various factors for poor efficacy of BCG in immune-competent adult individuals, prior exposure to environmental mycobacteria is thought to be an important and widely accepted cause for the poor efficacy of BCG vaccine in developing countries [10] [13]-[18]. Nevertheless, there is a tendency to retain BCG vaccination and to 
improve its immunogenic potential as BCG has been found heat stable and involve low production cost [19][23]. Provided the immunisation is correct, BCG is considered to be, largely, safe and tolerable. Normally a raised pimply blister develops at the site (upper right arm) of BCG injection as it is given intradermally. During this phase for a few weeks, the lesion may become bruised and painful for the vaccinated individual. Eventually, fluid accumulated at the surface of the pimple dries up giving rise to crusty surface. Thereafter within some weeks the lesion heals up ending with a scar at the site of injection. The degree of severity of the lesion may vary among the vaccinated individuals. Rarely, abscessed lesion at the site of injection may develop which may or may not be accompanied by lymph gland enlargement in armpit or neck. Again, in rare cases, there may occur lymphadenopathy. All of these clinical situations may be managed after consultation with the nurse and general physician. However, the major side effect of BCG vaccine is that it can cause local or disseminated infections in immuno-compromised individuals [24] [25].

\section{T Regulatory Cells}

$\mathrm{T}$ regulatory cells, predominately, are subtypes of $\mathrm{CD} 4^{+} \mathrm{T}$ helper cells that regulate the immune system by suppressing the proliferation of lymphocytes, production of cytokines and production of antibodies [26] [27]. These cells are identified better by detecting constitutive expression of CD25 (a chain of the interleukin-2 receptor) and the forkhead/winged helix transcription factor 3 (FoxP3). There are two subsets of Tregs: (i) natural Treg cells are derived from thymus during the development of immune system and have already immune suppressing capability; and (ii) adaptive/induced Tregs are generated in the periphery by stimulation of $\mathrm{CD}^{+} \mathrm{FoxP}^{+}$with prevailing antigens at the sub-optimal levels. Induced Tregs are further of two types (i) Tr1 and (ii) Th3 cells which have suppressive action, predominantly, through releasing immuno-suppressive cytokines IL-10 and TGF- $\beta$ respectively. Various markers of Treg cells are: CD25 (IL-2 $\alpha$ chain receptor), cytotoxic T lymphocyteassociated antigen 4 (CTLA-4), glucocorticoid-induced tumour necrosis factor receptor family-related gene (GITR), lymphocyte activation gene-3 (LAG-3/CD223), CD127 (IL-7 receptor), forkhead/winged-helix transcription factor box P3 (Foxp3), IL-10, TGF- $\beta$, CD45 (leucocyte common antigen/protein tyrosine phosphatase), CD39 (ectonucleoside triphosphate di-phosphohydrolase), CD73 (ecto-nucleosidase), CD26 (di-peptidyl peptidase) [27]. The target cells for suppression of immunity by Tregs are: $\mathrm{CD} 4^{+}, \mathrm{CD} 8^{+}, \mathrm{B}$ cells, dendritic cells, macrophages, NK (natural killer) cells, NKT (natural killer T cells), mast cells and osteoblasts, etc. [28]. Widely studied mechanisms [26] [29] of action of Tregs that have been reported are (Figure 1): (i) cell contact mediated suppression by Treg surface molecules CTLA4 and LAG-3. Here, CTLA-2 causes down regulation of expression of CD80/CD86 molecules and induction of production of indoleamine 2, 3-dioxygenase (IDO) in dendritic cell (DC). Also, it competitively inhibits interaction of co-stimulatory molecule CD28 on Con T cell with CD80/CD86 on DC, and thus results in inhibition of T cell activation through APC and T cell interaction. Similarly, binding of Treg LAG3 to MHC-II on DC also inhibits T cell activation. On the other hand, IDO in DC inhibits $\mathrm{T}$ cell growth by degrading tryptophan an essential amino acid needed for $\mathrm{T}$ cell growth. Further, kynurenine, a degraded product of tryptophan causes apoptosis of T cells; (ii) dampening of the activation of antigen presenting cells by cytokines IL-10, TGF- $\beta$ and IL-35 secreted by Tregs. These cytokines also inhibit T cell proliferation. On the other hand, IL-10 and TGF- $\beta$ support growth of Tregs as well; (iii) lytic/apoptotic deletion of T cell by perforin and granzyme produced by Tregs; (iv) arrest of T cell proliferation by depletion of growth factor IL-2 by its consumption by Tregs due to higher affinity as well as higher density of IL-2 receptors on these cells and (v) adenosine, produced through degradation of ATP/ADP/AMP by ecto-enzymes (CD39/ CD73) present on Tregs, interacts with $\mathrm{T}$ as well as dendritic cells and induces cAMP production in them. The cAMP thus produced causes $\mathrm{T}$ cell cycle arrest.

Thus, there exist several subsets of Tregs and they have arsenal of mechanisms for causing immunosuppression. Further, understanding of when, where, in what situation, what antigen, what subset of Tregs and what mechanism(s) would come into action for maintaining homeostasis during the immune response against mycobacteria is highly needed. Knowledge of these aspects of Tregs mediated immunosuppression might play a crucial role in developing immune-modulating strategies, including vaccine against tuberculosis.

\section{T Regulatory Cells and Efficacy of BCG}

There are reports [30]-[32] pointing out that Tregs could interfere with BCG mediated protection against TB. Tregs are known to be induced by environmental mycobacteria [33] [34], BCG [35]-[39] and M. tuberculosis 


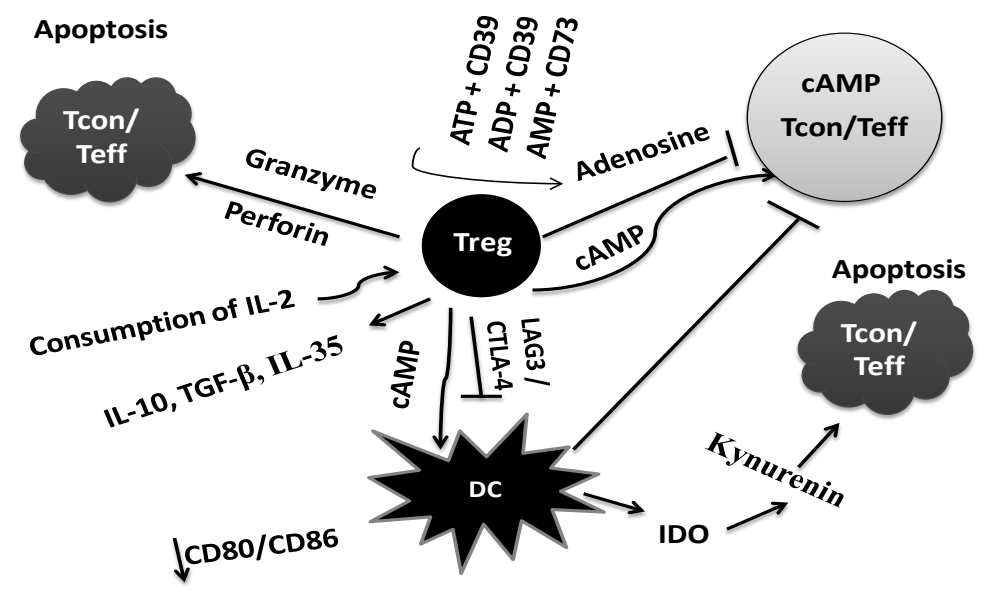

Figure 1. Effector mechanisms of T regulatory cell. ATP: adenosine triphosphatre; ADP: adenosine diphosphate; AMP: adenosine monophosphate; cAMP: cyclic adenosine monophosphate; DC: dendritic cell; Tcov: conventional T cell; Teff: effector T cell; TGF- $\beta$ : transforming growth factor; CTLA4: cytotoxic T lymphocyte-associated antigen 4; LAG3: lymphocyte activation gene-3 and IDO: indoleamine 2, 3-dioxygenase.

infection [40]-[47]. Pre-exposure of the host to environmental mycobacteria may induce Tregs against antigens, common to environmental mycobacteria, BCG and M. tuberculosis. Such sensitized Tregs may further be stimulated by subsequent vaccination with BCG and by M. tuberculosis infection. Thus, Tregs induced first by environmental mycobacteria may initiate the process leading towards down modulation of the efficacy of BCG vaccine. However, when there are no environmental mycobacteria, there may be scanty pre induced Tregs available for stimulation by BCG vaccination. This in turn may cause, relatively, more stimulation of IFN- $\gamma$ producing effector T cells after BCG vaccination. Hence, after infection, $M$. tuberculosis may be eradicated or contained by IFN $-\gamma$ activated macrophages. On the other hand, macrophages and dendritic cells may produce more IL-10 and TGF- $\beta$ on interaction with environmental mycobacteria which in turn may cause induction of Tregs. Subsequently, immunisation with BCG might activate naive as well as induced Tregs more when compared to IFN- $\gamma$ producer effector T cells resulting in failure for containing the $M$. tuberculosis on infection

\section{Remedies to Counter the Dampening Effect of Tregs on the Efficacy of BCG}

To understand the down modulating influence of Tregs on the performance of BCG vaccine against tuberculosis, a strategy to concomitantly attenuate Tregs with anti-CD25 antibodies during immunization of mice with BCG was attempted by Jaron et al. [30]. Wherein, a limited positive impact on the protective efficacy of BCG was noticed. This is thought to be due to insufficient elimination of Tregs with low CD25 surface expression or due to transient nature of CD25 down modulation.

Several studies have indicated that boosting of BCG primed immune response by down modulation of CD4 ${ }^{+}$ Tregs could be a promising approach (Table 1; [31], [48]-[51]). However, a prime-boost vaccine candidate (MVA85A; a recombinant Vaccinia virus (Ankara) expressing M. tuberculosis derived 85A antigen), involving Tregs down regulating phenomenon along with boosting of $T$ cell mediated immunity for its efficacy [48]-[50], has recently failed towards providing protection against TB or MTB infection in human trials [52]. This failure promotes to speculate that Tregs may not be the only immune component involved towards down modulating the protective effect of BCG against tuberculosis; rather, regulatory components other than $\mathrm{CD} 4^{+}$Tregs could also contribute to this phenomenon.

A recent immunotherapeutic approach [53] using D4476 (4-[4-(2,3-dihydro-1,4-benzodioxin-6-yl)-5-(2-pyridinyl)-1H-imiodazol-2-yl]benzamide), a small molecule, to inhibit differentiation of Tregs has demonstrated enhancement in BCG efficacy to protect against tuberculosis. A further synergistic effect with a Th2 inhibitor ssuplatast tosylate ([3-[[4-(3-ethoxy-2-hydroxypropoxy) phenyl] amino]-3-oxopropyl] dimethylsulfonium 4-methylbenzenesulfonate) $\}$ was also observed. This appears to be a simple and cost-effective approach to promote efficacy of BCG vaccine. Since it is a first study of its kind, more investigations are warranted for its establishment. 
Table 1. Studies showing the effect of down modulation at the levels of $\mathrm{CD} 4^{+} \mathrm{T}$ regulatory cells on the efficacy of BCG as an anti tuberculosis vaccine.

\begin{tabular}{|c|c|c|c|}
\hline References & Observations & Animals & Remarks \\
\hline [30] & $\begin{array}{c}\text { Attenuation (by treating mice with anti CD25) of Treg cells } \\
\text { concomitant to BCG vaccination showed a positive, yet limited, } \\
\text { impact on the protective capacity of this vaccine against } \\
\text { M. Tuberculosis infection. }\end{array}$ & Mice & $\begin{array}{l}\text { Tregs do not represent the major cause of the } \\
\text { limited efficacy of BCG as a vaccine against } \\
\text { tuberculosis. }\end{array}$ \\
\hline [31] & $\begin{array}{l}\text { BCG primed subjects showed better performance } \\
\text { (as measured by IFN- } \gamma \text { response) followed by boosting with } \\
\text { Vaccinia virus Ankara expressing the M.tuberculosis antigen 85A } \\
\text { (MVA85A).This appears to be through the limiting effect } \\
\text { (through reduced production of TGF- } \beta \text { ) of MVA85A on } \\
\text { the number of circulating CD4 }{ }^{+} \mathrm{CD} 25^{\text {hi }} \text { FoxP3 }^{+} \text {T cells. }\end{array}$ & Humans & $\begin{array}{l}\text { This phenomenon indicates that Tregs affect } \\
\text { the performance of BCG and MVA85A } \\
\text { appears to be a potential adjuvant } \\
\text { for BCG efficacy }\end{array}$ \\
\hline [48] & $\begin{array}{l}\text { BCG vaccinees were found to be associated with higher } \\
\text { CD }{ }^{+} \text {CD25 }{ }^{\text {hi }} \text { CD } 39^{+} \text {T-cell levels in the periphery and a reduced } \\
\text { capacity to produce IL-17A. However, on boosting with viral } \\
\text { vector vaccine, consisting of MVA85A, induction of } \\
\text { IL-17A-producing T cells were observed in the peripheral blood. }\end{array}$ & Humans & $\begin{array}{l}\text { This phenomenon indicates that Tregs may } \\
\text { affect the composition of vaccine-induced } \\
\text { T-cells and that MVA85A appears to be a } \\
\text { potential adjuvant for BCG efficacy }\end{array}$ \\
\hline [49] & $\begin{array}{l}\text { Priming with BCG followed by boosting with Modified Vaccinia } \\
\text { virus Ankara expressing Antigen 85A (MVA85A) enhanced the } \\
\text { BCG induced response by post boosting dropping down of } \\
\text { CD } 25^{+} \text {CD } 39^{+} \mathrm{T} \text { regulatory cells along with reduction in } \\
\text { consumption of ATP and increase in percentages IFN- } \gamma \text { and IL-17 } \\
\text { double producing CD } 4^{+} \text {T cells (Th1). }\end{array}$ & Humans & $\begin{array}{c}\text { In vaccinated subjects, a positive } \\
\text { relationship between extracellular ATP level } \\
\text { and IFN } \gamma^{+} \text {Th17 number again indicated that } \\
\text { MVA85A appears to be a potential adjuvant } \\
\text { for BCG efficacy through down regulation } \\
\text { of CD39 } \\
\text { Tregs }\end{array}$ \\
\hline [50] & $\begin{array}{l}\text { Priming with BCG followed by boosting twice with AMM } \\
\text { [Ag85B-Mpt64 (190-198)-Mtb8.4] showed best protective effect, } \\
\text { against M.tuberculosis infection, among all groups (boosted once, } \\
\text { twice and thrice), through induction of antigen-specific IFN- } \gamma \text { and } \\
\text { IL-2 production and also down-regulation of CD4 }{ }^{+} \text {CD } 25^{+} \\
\text {FoxP3 }{ }^{+} \text {regulatory T cells. }\end{array}$ & Mice & $\begin{array}{l}\text { AMM [Ag85B-Mpt64 (190-198)-Mtb8.4] } \\
\text { appears to be a potential adjuvant } \\
\text { for BCG efficacy }\end{array}$ \\
\hline [51] & $\begin{array}{l}\text { Heterologous immunization, using bacillus Calmette-Gue'rin } \\
\text { (BCG) to prime and DNA-hsp } 65 \text { to boost or BCG to prime and } \\
\text { culture filtrate proteins (CFP)-CpG to boost, was found to im- } \\
\text { prove protection against M.tuberculosis infection. Improvement } \\
\text { was through induction of higher ratio of CD4 }{ }^{+} \text {conventional T } \\
\text { cells and CD4 }{ }^{+} \text {T regulatory cells along with reduced lung } \\
\text { morbidity. }\end{array}$ & Mice & $\begin{array}{c}\text { DNA-hsp } 65 \text { (BCG/DNA-hsp 65) or BCG to } \\
\text { prime and culture filtrate proteins } \\
\text { (CFP)-CpG to boost (BCG/CFP-CpG) } \\
\text { appears to be a potential adjuvant for BCG } \\
\text { efficacy }\end{array}$ \\
\hline [53] & $\begin{array}{l}\text { Inhibition of CD4 }{ }^{+} \text {Tregs response by D4476 } \\
\text { (4-[4-(2, 3-dihydro-1,4-benzodioxin-6-yl)-5-(2-pyridinyl)- } \\
\text { 1H-imiodazol-2-yl]benzamide), a small molecule, improves } \\
\text { efficacy of BCG against } M \text {. Tuberculosis infection. The efficacy is } \\
\text { further enhanced on simultaneous inhibition of Th2 response. }\end{array}$ & Mice & $\begin{array}{l}\text { Inhibition of Tregs response by small } \\
\text { molecules could help in enhancing the effi- } \\
\text { cacy of BCG }\end{array}$ \\
\hline
\end{tabular}

Apartly, some more strategies [18] that are worthwhile exploring are: (i) Tregs inducing BCG antigens, common among environmental mycobacteria, BCG and M.tuberculosis, need to be identified. This may open paths towards bettering of BCG vaccines by knocking out genes responsible for Tregs inducing proteins from BCG; (ii) recombinant BCG (rBCG) strains expressing Tregs down modulating proteins could help in improving protective immune response of BCG against $M$. tuberculosis infection.

\section{Apprehensions Concerning the Immune-Modulation at the Levels of Tregs to Improve BCG Efficacy}

While formulating strategies to improve the performance of BCG at the levels of Tregs, harmful side effects of such approaches need to be considered. Since dampening of Tregs may lead to suppression of Tregs functions in the host which in turn may make the individuals susceptible to develop clinical immunological disorders in the host, viz: induction of autoimmune diseases, allergy, asthma, failure of pregnancy, and aggravation of immunopathogenesis in already exsiting clinical conditions [54] leading to increased morbidity and mortality. There 
could also be severe side effects due to occurrence of "cytokine storm” due to elevated cytokine levels.

It is known that mycobacterial antigens have the potential to act as auto-antigens [55]-[57]. Since, Tregs are known to control autoimmunity, suppressing such cells may make the vaccinated individuals further prone to develop mycobacterial antigens induced autoimmune reactions.

\section{Conclusions}

Experimentally, modulations at the level of Tregs have been shown to be promising for bettering of BCG vaccine efficacy (Table 1). However, such strategies are also likely to impair immune homeostasis and hence, may cause immunological abnormalities like: deleterious autoimmune and inflammatory disorders. Keeping these possibilities in view, strategic studies to improve the performance of BCG through countering the down modulating effect of Tregs without causing the deleterious side effects are highly required

Since BCG is an inducer of Tregs, recruitment of Tregs at the site of immunization may occur as a result thereof. It would be interesting to understand the molecular phenomenon involved in recruitment of Tregs at the site of immunization as it may open paths to evolve some approach to inhibit local recruitment of Tregs without affecting their functions. Eventually, this may help in avoiding generalised systemic disturbance of immune homeostasis and thereby generation of clinical disorders.

Probably, a transient inhibition for Tregs functions could be worth adopting over Treg depleting approaches for boosting the efficacy of a vaccine. Regarding this, searching small molecules capable of down modulating functions of Tregs may be a better option because they have shorter half life for about a day when compared to monoclonal antibodies (with a half life of 14 - 21 days) and hence, may be used for transient inhibition.

Lastly, whatever may be the strategy to improve the performance of BCG through reducing the Tregs population, the ratio of Th1 type of CD4 cells and Tregs needs to be maintained to a level where causation of clinical immunological abnormalities must be minimal and the efficacy of BCG vaccine optimal. Evolving such a strategy appears to be a future challenge for developing anti TB vaccine.

\section{Acknowledgements}

Thanks to Juraj Ivanyi, Department of Oral Medicine \& Pathology, Guy's Campus, Medical and Dental Schools of Kings College, London, United Kingdom, for his constructive suggestions. Thanks Infolep, Amsterdam, The Netherlands, for helping in providing the scientific literature. Thanks to Ms Sonali Agrawal for her help in preparing the reference part. Thanks to Indian Council of Medical Research for routine facilities.

\section{Conflict of Interest}

There is no conflict of interest regarding this manuscript.

\section{References}

[1] van Crevel, R., Ottenhoff, T.H. and van der Meer, J.W. (2002) Innate immunity to Mycobacterium tuberculosis. Clinical Microbiology Reviews, 15, 294-309. http://dx.doi.org/10.1128/CMR.15.2.294-309.2002

[2] WHO (2014) Global Tuberculosis Report 2014. WHO/HTM/TB/2014.08, World Health Organization, Geneva. http://www.who.int/tb/publications/global_report/en/

[3] Zumla, A., Raviglione, M., Hafner, R. and von Reyn, C.F. (2013) Tuberculosis. The New England Journal of Medicine, 368, 745-755. http://dx.doi.org/10.1056/NEJMra1200894

[4] Ray, S., Talukdar, A., Kundu, S., Khanra, D. and Sonthalia, N. (2013) Diagnosis and Management of Miliary Tuberculosis: Current State and Future Perspectives. Journal of Therapeutics and Risk Management, 9, 9-26. http://dx.doi.org/10.2147/TCRM.S29179

[5] Narasimhan, P., Wood, J., MacIntyre, C.R. and Mathai, D. (2013) Risk Factors for Tuberculosis. Pulmonary Medicine, 2013, Article ID: 828939. http://dx.doi.org/10.1155/2013/828939

[6] Lawn, S.D. and Zumla, A.I. (2011) Tuberculosis. The Lancet, 378, 57-72. http://dx.doi.org/10.1016/S0140-6736(10)62173-3

[7] Chang, K.-C. and Yew, W.-W. (2013) Management of Difficult Multidrug-Resistant Tuberculosis and Extensively Drug-Resistant Tuberculosis: Update 2012. Respirology, 18, 8-21. http://dx.doi.org/10.1111/j.1440-1843.2012.02257.x

[8] TB Alliance: Economic Impact of TB. http://www.tballiance.org/why/economic-impact.php 
[9] Luca, S. and Mihaescu, T. (2013) History of BCG Vaccine. Maedica: A Journal of Clinical Medicine, 8, 53-58. http://www.ncbi.nlm.nih.gov/pmc/articles/PMC3749764/pdf/maed-08-53.pdf

[10] Andersen, P. and Doherty, T.M. (2005) The Success and Failure of BCG-Implications for a Novel Tuberculosis Vaccine. Nature Reviews Microbiology, 3, 656-662. http://dx.doi.org/10.1038/nrmicro1211

[11] Fine, P.E. (1995) Variation in Protection by BCG: Implications of and for Heterologous Immunity. Lancet, 346, 13391345. http://dx.doi.org/10.1016/S0140-6736(95)92348-9

[12] Ottenhoff, T.H. and Kaufmann, S.H. (2012) Vaccines against Tuberculosis: Where Are We and Where Do We Need to Go? PLoS Pathogens, 8, e1002607. http://dx.doi.org/10.1371/journal.ppat.1002607

[13] Fine, P.E., Floyd, S., Stanford, J.L., Nkhosa, P., Kasunga, A., Chaguluka, S., Warndorff, D.K., Jenkins, P.A., Yates, M. and Ponnighaus, J.M. (2001) Environmental Mycobacteria in Northern Malawi: Implications for the Epidemiology of Tuberculosis and Leprosy. Epidemiology and Infection, 126, 379-387. http://dx.doi.org/10.1017/S0950268801005532 http://www.ncbi.nlm.nih.gov/pmc/articles/PMC2869706/pdf/11467795.pdf

[14] Brandt, L., Feino Cunha, J., Weinreich Olsen, A., Chilima, B., Hirsch, P., Appelberg, R. and Andersen, P. (2002) Failure of the Mycobacterium bovis BCG Vaccine: Some Species of Environmental Mycobacteria Block Multiplication of BCG and Induction of Protective Immunity to Tuberculosis. Infection and Immunity, 70, 672-678. http://www.ncbi.nlm.nih.gov/pmc/articles/PMC127715/pdf/1144.pdf http://dx.doi.org/10.1128/IAI.70.2.672-678.2002

[15] Ho, P., Wei, X. and Seah, G.T. (2010) Regulatory T Cells Induced by Mycobacterium chelonae Sensitization Influence Murine Responses to Bacille Calmette-Guérin. Journal of Leukocyte Biology, 88, 1073-1080. http://dx.doi.org/10.1189/jlb.0809582

[16] Primm, T.P., Lucero, C.A. and Falkinham III, J.O. (2004) Health Impacts of Environmental Mycobacteria. Clinical Microbiology Reviews, 17, 98-106. http://dx.doi.org/10.1128/CMR.17.1.98-106.2004

[17] Weir, R.E., Black, G.F., Nazareth, B., Floyd, S., Stenson, S., Stanley, C., Branson, K., Sichali, L., Chaguluka, S.D., Donovan, L., Crampin, A.C., Fine, P.E. and Dockrell, H.M. (2006) The Influence of Previous Exposure to Environmental Mycobacteria on the Interferon-Gamma Response to Bacille Calmette-Guérin Vaccination in Southern England and Northern Malawi. Clinical \& Experimental Immunology, 146, 390-399. http://dx.doi.org/10.1111/j.1365-2249.2006.03222.x

[18] Parkash, O. (2014) How to Avoid the Impact of Environmental Mycobacteria towards the Efficacy of BCG Vaccination against Tuberculosis? International Journal of Mycobacteriology, 3, 1-4. http://dx.doi.org/10.1016/j.ijmyco.2014.01.006

[19] Rouanet, C., Debrie, A.S., Lecher, S. and Locht, C. (2009) Subcutaneous Boosting with Heparin Binding Haemagglutinin Increases BCG-Induced Protection against Tuberculosis. Microbes and Infection, 11, 995-1001. http://dx.doi.org/10.1016/j.micinf.2009.07.005

[20] Brandt, L., Skeiky, Y.A., Alderson, M.R., Lobet, Y., Dalemans, W., Turner, O.C., Basaraba, R.J., Izzo, A.A., Lasco, T.M., Chapman, P.L., Reed, S.G. and Orme, I.M. (2004) The Protective Effect of the Mycobacterium bovis BCG Vaccine Is Increased by Coadministration with the Mycobacterium tuberculosis 72-Kilodalton Fusion Polyprotein Mtb72F in M. tuberculosis-Infected Guinea Pigs. Infection and Immunity, 72, 6622-6632. http://dx.doi.org/10.1128/IAI.72.11.6622-6632.2004

[21] Reed, S.G., Coler, R.N., Dalemans, W., Tan, E.V., DeLa Cruz, E.C., Basaraba, R.J., Orme, I.M., Skeiky, Y.A., Alderson, M.R., Cowgill, K.D., Prieels, J.P., Abalos, R.M., Dubois, M.C., Cohen, J., Mettens, P. and Lobert, Y. (2009) Defined Tuberculosis Vaccine, Mtb72F/AS02A, Evidence of Protection in Cynomolgus Monkeys. Proceedings of the National Academy of Sciences of the United States of America, 106, 2301-2306. http://dx.doi.org/10.1073/pnas.0712077106

[22] Rahman, M.J. and Fernandez, C. (2009) Neonatal Vaccination with Mycobacterium bovis BCG: Potential Effects as a Priming Agent Shown in a Heterologous Prime-Boost Immunization Protocol. Vaccine, 27, 4038-4046. http://dx.doi.org/10.1016/j.vaccine.2009.04.027

[23] Dietrich, J., Andersen, C., Rappuoli, R., Doherty, T.M., Jensen, C.G. and Andersen, P. (2006) Mucosal Administration of Ag85B-ESAT-6 Protects against Infection with Mycobacterium tuberculosis and Boosts Prior Bacillus CalmetteGuerin Immunity. Journal of Immunology, 177, 6353-6360. http://dx.doi.org/10.4049/jimmunol.177.9.6353

[24] World Health Organization (2004) BCG Vaccine. Weekly Epidemiological Record, 79, 27-38. http://www.who.int/wer

[25] Bellet, J.S. and Prose, N.S. (2005) Skin Complications of Bacillus Calmette-Guérin Immunization. Current Opinion in Infectious Diseases, 18, 97-100. http://dx.doi.org/10.1097/01.qco.0000160895.97362.4f http://journals.lww.com/co-infectiousdiseases/Abstract/2005/04000/Skin_complications_of_Bacillus_Calmette_Gu_rin .3.aspx

[26] Mills, K.H. (2004) Regulatory T Cells: Friend or Foe in Immunity to Infection? Nature Reviews Immunology, 4, 841- 
855. http://www.nature.com/nri/journal/v4/n11/full/nri1485.html http://dx.doi.org/10.1038/nri1485

[27] Sakaguchi, S., Wing, K., Onishi, Y., Prieto-Martin, P. and Yamaguchi, T. (2009) Regulatory T Cells: How Do They Suppress Immune Responses? International Immunology, 21, 1105-1111. http://dx.doi.org/10.1093/intimm/dxp095

[28] Sanchez, A.M. and Yang, Y. (2011) The Role of Natural Regulatory T Cells in Infection. Immunologic Research, 49, 124-134. http://dx.doi.org/10.1007/s12026-010-8176-8

[29] Schmitt, E.G. and Williams, C.B. (2013) Generation and Function of Induced Regulatory T Cells. Frontiers in Immunology, 4, 1-13. http://dx.doi.org/10.3389/fimmu.2013.00152

[30] Jaron, B., Maranghi, E., Leclerc, C. and Majlessi, L. (2008) Effect of Attenuation of Treg during BCG Immunization on Anti-Mycobacterial Th1 Responses and Protection against Mycobacterium tuberculosis. PLoS ONE, 3, e2833. http://dx.doi.org/10.1371/journal.pone.0002833

[31] Fletcher, H.A., Pathan, A.A., Berthoud, T.K., Dunachie, S.J., Whelan, K.T., Alder, N.C., Sander, C.R., Hill, A.H. and McShane, H. (2008) Boosting BCG Vaccination with MVA85A Down-Regulates the Immunoregulatory Cytokine TGFBeta1. Vaccine, 26, 5269-5275. http://dx.doi.org/10.1016/j.vaccine.2008.07.040

[32] Coleman, M.M., Keane, J. and Mills, K.H. (2010) Editorial: Tregs and BCG-Dangerous Liaisons in TB. Journal of Leukocyte Biology, 88, 1067-1069. http://www.jleukbio.org/content/88/6/1067.full.pdf+html

[33] Joosten, S.A. and Ottenhoff, T.H. (2008) Human CD4 and CD8 Regulatory T Cells in Infectious Diseases and Vaccination. Human Immunology, 69, 760-770. http://dx.doi.org/10.1016/j.humimm.2008.07.017

[34] Zuany-Amorim, C., Sawicka, E., Manlius, C., Le Moine, A., Brunet, L.R., Kemeny, D.M., Bowen, G., Rook, G. and Walker, C. (2002) Suppression of Airway Eosinophilia by Killed Mycobacterium vaccae-Induced Allergen-Specific Regulatory T-Cells. Nature Medicine, 8, 625-629. http://dx.doi.org/10.1038/nm0602-625

[35] Quinn, K.M., McHugh, R.S., Rich, F.J., Goldsack, L.M., de Lisle, G.W., Buddle, B.M., Delahunt, B. and Kirman, J.R. (2006) Inactivation of $\mathrm{CD}^{+} \mathrm{CD} 25^{+}$Regulatory T Cells during Early Mycobacterial Infection Increases Cytokine Production but Does Not Affect Pathogen Load. Immunology and Cell Biology, 84, 467-474. http://dx.doi.org/10.1111/j.1440-1711.2006.01460.x

[36] Li, Q. and Shen, H.H. (2009) Neonatal Bacillus Calmette-Guérin Vaccination Inhibits de novo Allergic Inflammatory Response in Mice via Alteration of $\mathrm{CD} 4^{+} \mathrm{CD} 25^{+}$T-Regulatory Cells. Acta Pharmacologica Sinica, 30, 125-133. http://dx.doi.org/10.1038/aps.2008.3

[37] Kim, Y.J., Kim, H.J., Kang, M.J., Yu, H.S., Seo, J.H., Kim, H.Y., Park, S.J., Lee, Y.C. and Hong, S.J. (2014) Bacillus Calmette-Guérin Suppresses Asthmatic Responses via $\mathrm{CD} 4{ }^{+} \mathrm{CD} 25^{+}$Regulatory T Cells and Dendritic Cells. Allergy Asthma and Immunology Research, 6, 201-207.

[38] Laćan, G., Dang, H., Middleton, B., Horwitz, M.A., Tian, J., Melega, W.P. and Kaufman, D.L. (2013) Bacillus CalmetteGuerin Vaccine-Mediated Neuroprotection Is Associated with Regulatory T-Cell Induction in the 1-methyl-4-phenyl1,2,3,6-Tetrahydropyridine Mouse Model of Parkinson’s Disease. Journal of Neuroscience Research, 91, 1292-1302. http://dx.doi.org/10.1002/jnr.23253

[39] Boer, M.C., van Meijgaarden, K.E., Bastid, J., Ottenhoff, T.H. and Joosten, S.A. (2013) CD39 Is Involved in Mediating Suppression by Mycobacterium bovis BCG-Activated Human CD8 ${ }^{+}$CD39 ${ }^{+}$Regulatory T Cells. European Journal of Immunology, 43, 1925-1932. http://dx.doi.org/10.1002/eji.201243286

[40] Hougardy, J.M., Place, S., Hildebrand, M., Drowart, A., Debrie, A.S., Locht, C. and Mascart, F. (2007) Regulatory T-Cells Depress Immune Responses to Protective Antigens in Active Tuberculosis. American Journal of Respiratory and Critical Care Medicine, 176, 409-416. http://dx.doi.org/10.1164/rccm.200701-084OC

[41] Marin, N.D., París, S.C., Vélez, V.M., Rojas, C.A., Rojas, M. and García, L.F. (2010) Regulatory T Cell Frequency and Modulation of IFN-Gamma and IL-17 in Active and Latent Tuberculosis. Tuberculosis, 90, 252-261. http://dx.doi.org/10.1016/j.tube.2010.05.003

[42] Sharma, P.K., Saha, P.K., Singh, A., Sharma, S.K., Ghosh, B. and Mitra, D.K. (2009) FoxP3 ${ }^{+}$Regulatory T Cells Suppress Effector T-Cell Function at Pathologic Site in Miliary Tuberculosis. American Journal of Respiratory and Critical Care Medicine, 179, 1061-1070. http://dx.doi.org/10.1164/rccm.200804-529OC

[43] Chen, X., Zhou, B., Li, M., Deng, Q., Wu, X., Le, X., Wu, C., Larmonier, N., Zhang, W., Zhang, H., Wang, H. and Katsanis, E. (2007) $\mathrm{CD}^{+} \mathrm{CD}^{+} 5^{+} \mathrm{FoxP}^{+}$Regulatory T Cells Suppress Mycobacterium tuberculosis Immunity in Patients with Active Disease. Clinical Immunology, 123, 50-59. http://dx.doi.org/10.1016/j.clim.2006.11.009

[44] Guyot-Revol, V., Innes, J.A., Hackforth, S., Hinks, T. and Lalvani, A. (2006) Regulatory T Cells Are Expanded in Blood and Disease Sites in Patients with Tuberculosis. American Journal of Respiratory and Critical Care Medicine, 173, 803-810. http://dx.doi.org/10.1164/rccm.200508-1294OC

[45] Ribeiro-Rodrigues, R., Resende Co, T., Rojas, R., Toossi, Z., Dietze, R., Boom, W.H., Maciel, E. and Hirsch, C.S. (2006) A Role for $\mathrm{CD} 4^{+} \mathrm{CD} 25^{+} \mathrm{T}$ Cells in Regulation of the Immune Response during Human Tuberculosis. Clinical \& Experimental Immunology, 144, 25-34. http://dx.doi.org/10.1111/j.1365-2249.2006.03027.x 
[46] Li, L., Lao, S.H. and Wu, C.Y. (2007) Increased Frequency of CD4 $4^{+}$CD25 ${ }^{\text {high }}$ Treg Cells Inhibit BCG-Specific Induction of IFN- $\gamma$ by CD4 ${ }^{+}$T Cells from TB Patients. Tuberculosis, 87, 526-534. http://dx.doi.org/10.1016/j.tube.2007.07.004

[47] Li, L. and Wu, C.Y. (2008) CD $4^{+} \mathrm{CD} 25^{+}$Treg Cells Inhibit Human Memory $\gamma \delta$ T Cells to Produce IFN- $\gamma$ in Response to M. tuberculosis Antigen ESAT-6. Blood, 111, 5629-5636. http://dx.doi.org/10.1182/blood-2008-02-139899

[48] de Cassan, S.C., Pathan, A.A., Sander, C.R., Minassian, A., Rowland, R., Hill, A.V., McShane, H. and Fletcher, H.A. (2010) Investigating the Induction of Vaccine-Induced Th17 and Regulatory T Cells in Healthy, Mycobacterium bovis BCG-Immunized Adults Vaccinated with a New Tuberculosis Vaccine, MVA85A. Clinical and Vaccine Immunology, 17, 1066-1073. http://dx.doi.org/10.1128/CVI.00047-10

[49] Griffiths, K.L., Pathan, A.A., Minassian, A.M., Sander, C.R., Beveridge, N.E., Hill, A.V., Fletcher, H.A. and McShane, H. (2011) Th1/Th17 Cell Induction and Corresponding Reduction in ATP Consumption Following Vaccination with the Novel Mycobacterium tuberculosis Vaccine MVA85A. PLoS ONE, 6, e23463. http://dx.doi.org/10.1371/journal.pone.0023463

[50] Luo, Y., Jiang, W., Da, Z., Wang, B., Hu, L., Zhang, Y., An, R., Yu, H., Sun, H., Tang, K., Tang, Z., Wang, Y., Jing, T. and Zhu, B. (2012) Subunit Vaccine Candidate AMM Down-Regulated the Regulatory T Cells and Enhanced the Protective Immunity of BCG on a Suitable Schedule. Scandinavian Journal of Immunology, 75, 293-300. http://dx.doi.org/10.1111/j.1365-3083.2011.02666.x

[51] Fedatto, P.F., Sérgio, C.A., Paula, M.O., Gembre, A.F., Franco, L.H., Wowk, P.F., Ramos, S.G., Horn, C., Marchal, G., Turato, W.M., Silva, C.L., da Fonseca, D.M. and Bonato, V.L. (2012) Protection Conferred by Heterologous Vaccination against Tuberculosis Is Dependent on the Ratio of $\mathrm{CD}^{+} / \mathrm{CD}^{+}$Foxp3 $^{+}$Cells. Immunology, 137, 239-248. http://dx.doi.org/10.1111/imm.12006

[52] Tameris, M.D., Hatherill, M., Landry, B.S., Scriba, T.J., Snowden, M.A., Lockhart, S., Shea, J.E., McClain, J.B., Hussey, G.D., Hanekom, W.A., Mahomed, H., McShane, H., and the MVA85A 020 Trial Study Team (2013) Safety and Efficacy of MVA85A, a New Tuberculosis Vaccine, in Infants Previously Vaccinated with BCG: A Randomised, Placebo-Controlled Phase 2b Trial. Lancet, 381, 1021-1028. http://dx.doi.org/10.1016/S0140-6736(13)60177-4

[53] Bhattacharya, D., Dwivedi, V.P., Kumar, S., Reddy, M.C., Van Kaer, L., Moodley, P. and Das, G. (2014) Simultaneous Inhibition of T Helper 2 and T Regulatory Cell Differentiation by Small Molecules Enhances Bacillus CalmetteGuerin Vaccine Efficacy against Tuberculosis. Journal of Biological Chemistry, 289, 33404-33411. http://dx.doi.org/10.1074/jbc.M114.600452

[54] Rouse, B.T. (2007) Regulatory T Cells in Health and Disease. Journal of Internal Medicine, 262, 78-95. http://dx.doi.org/10.1111/j.1365-2796.2007.01836.x

[55] Torisu, M., Miyahara, T., Shinohara, N., Ohsato, K. and Sonozaki, H. (1978) A New Side Effect of BCG Immunotherapy: BCG Induced Arthritis in Man. Cancer Immunology, Immunotherapy, 5, 77-83. http://link.springer.com/article/10.1007\%2FBF00199980 http://dx.doi.org/10.1007/BF00199980

[56] Shoenfeld, Y. and Isenberg, D.A. (1988) Mycobacteria and Autoimmunity. Immunology Today, 9, 178-182. http://dx.doi.org/10.1016/0167-5699(88)91294-7

[57] Karopoulos, C., Rowley, M.J., Handley, C.J. and Strugnell, R.A. (1995) Antibody Reactivity to Mycobacterial 65 kDa Heat Shock Protein: Relevance to Autoimmunity. Journal of Autoimmunity, 8, 235-248. http://dx.doi.org/10.1006/jaut.1995.0018 